Volume. 2 No. 1 tahun 2020

Mei 2021 - November 2021
ISSN (online): 2722-2055 https://jurnal.umj.ac.id/index.php/AS-
AS-SYIFA: Jurnal Pengabdian dan

Pemberdayaan Kesehatan

Masyarakat

\title{
Upaya Menurunkan Tekanan Darah pada Lansia Melalui Terapi Shalat Dhuha
}

\section{Efforts To Reduce Blood Pressure in The Elderly Through The Dhuha Prayer Therapy}

\author{
${ }^{1)}$ Dian Istiana, ${ }^{2)}$ Dewi Nur Sukma Purqoti", ${ }^{3)}$ Fitri Romadonika, ${ }^{4)}$ Mita Pusparini \\ ${ }^{1,2,3,4)}$ Program Studi Pendidikan Ners, Stikes Yarsi Mataram \\ email: purqotidewi87@gmail.com
}

\begin{abstract}
Abstrak
Hipertensi sudah menjadi masalah kesehatan yang cukup tinggi di dunia tidak hanya ditemukan pada Negara maju tapi dijumpai juga pada negara- negara berkembang. Ketika tensi berada pada angka diatas $140 \mathrm{mmHg}$ untuk tekanan darah sistolik dan di atas angka $90 \mathrm{mmHg}$ untuk tekanan darah diastolik maka kondisi inilah disebut hipetensi. Hipertensi banyak dijumpai pada lansia, beberapa faktor yang melatarbelakangi lansia mengidap hipertensi antara lain faktor kepekaan terhadap kadar garam, reaktivitas pembuluh darah terhadap vasokonstriktor, pola makan, kebiasaan merokok, stress emosi, kegemukan dan lain-lain. Adapun tata laksana pengendalian tekanan darah tinggi ada dua jenis yaitu pengebotan medis dengan obat-obatan dan pengendalian tanpa obat atau teknik relaksasi yang bertujuan untuk merelaks kan otot-otot dan organ sehingga mampu menurunkan tekanan darah. Tujuan dari kegiatan pengabdian ini adalah pengenalan cara pengendalian tekanan darah berupa pelaksanaan terapi shalat dhuha. Panti Sosial Tresna Werdha Provinsi Nusa Tenggara Barat merupakan mitra pada pelaksanaan pengabdian ini. Metode yang dikukan dalam kegiatan pengabdian ini dengan pelaksanaan terapi shalat dhuha selama 7 hari berturut-turut sebanyak 4 rokaat setiap harinya. Hasil dari kegiatan pengabdian ini didapatkan penurunan tekanan darah setelah dilakukannya terapi shalat dhuha. Setelah pelaksanaan kegiatan pengabdian ini diharapkan terapi shalat dhuha tetap dilaksanakan secara rutin untuk mengendalikan tekanan darah agar tetap stabil.
\end{abstract}

Kata Kunci :Hipertensi, terapi shalat dhuha, lansia.

\begin{abstract}
Hypertension has become a fairly high health problem in the world not only found in developed countries but also in developing countries. When tension is above $140 \mathrm{mmHg}$ for systolic blood pressure and above $90 \mathrm{mmHg}$ for diastolic blood pressure then this condition is called hipetension. Hypertension is found in the elderly, several factors behind the elderly have hypertension, among others, factors of sensitivity to salt levels, vascular reactivity to vasoconstrictor, diet, smoking habits, emotional stress, obesity and others. As for the procedure of controlling high blood pressure there are two types of medical sabotage with drugs and control without drugs or relaxation techniques aimed at relaxing the muscles and organs so as to lower blood pressure. The purpose of this devotional activity is the introduction of a way of controlling blood pressure in the form of the implementation of dhuha prayer therapy. Tresna Werdha Social Home in West Nusa Tenggara Province is a partner in the implementation of this service. The method carried out in this devotional activity with the implementation of dhuha prayer therapy for 7 consecutive days as many as 4 rokaat every day. The result of this devotional activity was obtained a decrease in blood pressure after the dhuha prayer therapy. After the implementation of this devotional activity, it is expected that dhuha prayer therapy will still be carried out regularly to control blood pressure in order to remain stable.
\end{abstract}

Keywords: Hypertension, dhuha prayer therapy, the elderly. 
Volume. 2 No. 1 tahun 2020

Mei 2021 - November 2021
ISSN (online): 2722-2055 https://jurnal.umj.ac.id/index.php/ASSYIFA
AS-SYIFA: Jurnal Pengabdian dan Pemberdayaan Kesehatan

Masyarakat

\section{Pendahuluan}

Berdasarkan data WHO (World Health Organization) diperkirakan sampai tahun 2025 tingkat terjadinya tekanan darah tinggi akan bertambah $60 \%$, dan akan mempengaruhi 1,56 milyar penduduk di seluruh dunia (Depkes RI, 2016). Hasil Riset Kesehatan Dasar (Riskesdas) indonesia tahun 2018 menunjukkan masih banyaknya kasus hipertensi di masyarakat belum terdiagnosis. Pada usia $>18$ tahun ditemukan prevalensi hipertensi sebanyak $34,1 \%$ dimana hanya $7,2 \%$ yang mengetahui sedang menyandang darah tinggi dan hanya $8,8 \%$ mengkonsumsi obat hipertensi (Riskesdas, 2018), sedangkan pada lansia yang ada di panti werdha diketahui tekanan darah sistol mencapai $150-160 \mathrm{mmHg}$ dan diastol mencapai 90-100 $\mathrm{mmHg}$, dan diketahui rata-rata tekanan darah sistol setelah melaksanakan sholat dhuha sistol 140-150 mmHg dan diastol mencapai 80-90 mmHg.

Berdasarkan data di Provinsi NTB diperkirakan sebanyak 358.110 jiwa dan yang mendapatkan pelayanan sebesar 56.107 jiwa (15,67\%). Jumlah penderita hipertensi tahun 2018 di puskesmas sekota mataram berjumlah 37.190 kasus (Dikes Prov NTB, 2019). Faktor yang melatarbelakangi lansia mengidap hipertensi selain dikarenakan penurunan fungsi organ karena proses penuaan tetapi juga diakarenakan beberapa faktor antara lain kepekaan terhadap kadar garam, reaktivitas pembuluh darah terhadap vasokonstriktor, pola makan, kebiasaan merokok, stress emosi, kegemukan dan lain-lain. (Dina T, Elperin, et al, 2013).

Hipertensi yang tidak terkontrol dapat menyebabkan kecacatan bahkan kematian, hal ini dapat dicegah dengan menjaga tekanan darah stabil atau di bawah 140/90 mmHg. Adapun alternatif yang dilakukan untuk menjaga tensi tetap stabil dapat berupa intervensi farmakologis dan non farmakologis. Intervensi farmakologis berupa tatalaksana dengan obatobatan medis berupa obat anti hipertensi. Sedangkan intervensi non farmakologis berupa tatalaksana tanpa obat medis, salah satunya yaitu dengan teknik relaksasi. Ketika semua organ dalam tubuh kita rileks dan tidak terjadi ketegangan akan berdampak pada respon saraf simpatis untuk menurunkan produksi hormon epinefrin dan norepinefrin dalam darah sehingga meminimalisir resiko stress dan meningkatnya denyut jantung abnormal (Corwin dalam Azizah, 2011). Salah satu yang bisa dilakukan untuk memberikan ketenangan dan kenyamanan adalah dengan selalu mengingat Allah, salah satu upaya kita untuk selalu memngingat Allah dapat dipicu dengan selalu melakukan shalat dhuha.

Adapun tata cara shalat dhuha yang dianjurkan minimal dilaksanakan 2 rakaat dan maksimal 12 rakaat, dengan cara berjamaah dan tidak berjamaah (munfarid). Adapun tatacaranya :

1. Niat sholat dhuha diucapkan didalam hati dengan bersamaan pada saat takbir.

2. Takbiratul ihram dan membaca iftitah dan fatihah

3. Membaca surah pendek dalam alquran, dimana untuk rakaat pertama sebaiknya dibaca suarah yaitu Asy-Syam atau Al-Kafirun dan untuk di rakaat kedua sebaiknya dibaca yakni surat Al-Ikhlas atau surat waddhuha

4. Ruku sambil membcakan tasbih dibaca tiga kali

5. I'tidal dan dengan membca bacaan I'tidal

6. Sujud pertama dengan membaca bacaan sujud

7. Duduk diantara dua sujud

Setelah selsai rokaat pertama maka dilanjutkan rakaat kedua dengan cara yang sama seperti rokaat pertama kemudian pada Tasyahhud akhir dan diakhiri dengan salam.

Shalat dhuha yang dilakukan dengan niat ikhlas akan memperbaiki emosional positif yang akan tercermin dikehidupan yang sehat. Shalat dhuha berpengaruh terhadap fisiologi tekanan darah karena rileks yang dirasakan ketika melakukan sholat dhuha dapat mengaktivasi system saraf parasimpatis. Tujuan dari kegiatan pengabdian ini adalah memperkenalkan cara pengendalian hipertensi berupa pelaksanaan terapi shalat dhuha di Panti Sosial Tresna 
AS-SYIFA: Jurnal Pengabdian dan Pemberdayaan Kesehatan Masyarakat

Werdha Provinsi Nusa Tenggara Barat. Adapun manfaat dari kegiatan pengabdian ini salah satunya responden mampu mengendalikan tekanan darahnya dalam keadaan stabil dengan metode non farmakologi, menjadikan responden lebih segar dan bersemangat karena dilakukan di pagi hari.

\section{Metode}

Kegiatan pengabdian masyarakat ini telah dilaksanakan pada tanggal 5-11 maret 2020 pukul 09.00 wita di Panti Sosial Tresna Werdha Provinsi Nusa Tenggara Barat dengan target sasaran mencapai 16 Orang Lansia. Adapun teknik pelaksanaan kegiatan pengabdian ini adalah :

1. Tahap awal

Pada tahap ini dilakukan pengukuran tekanan darah sebelum dilakukan terapi shalat dhuha

2. Tahap Pelaksanaan terapi shalat dhuha

Shalat dhuha dilakukan selama 7 hari berturut-turut dan dilakukan 4 rokaat setiap harinya.

3. Tahap setelah pelaksanaan

Pada tahap ini dilakukan pengukuran tekanan darah setelah pelaksananaan terapi shalat dhuha

4. Tahap Akhir

Evaluasi dilakukan setelah 2 minggu pelaksanaan pengabdian dengan mengukur kembali tekanan darah lansia. Monitoring dilaksanakan secara berkelanjutan oleh petugas yang ada di panti tersebut. 


\section{Hasil Dan Pembahasan}

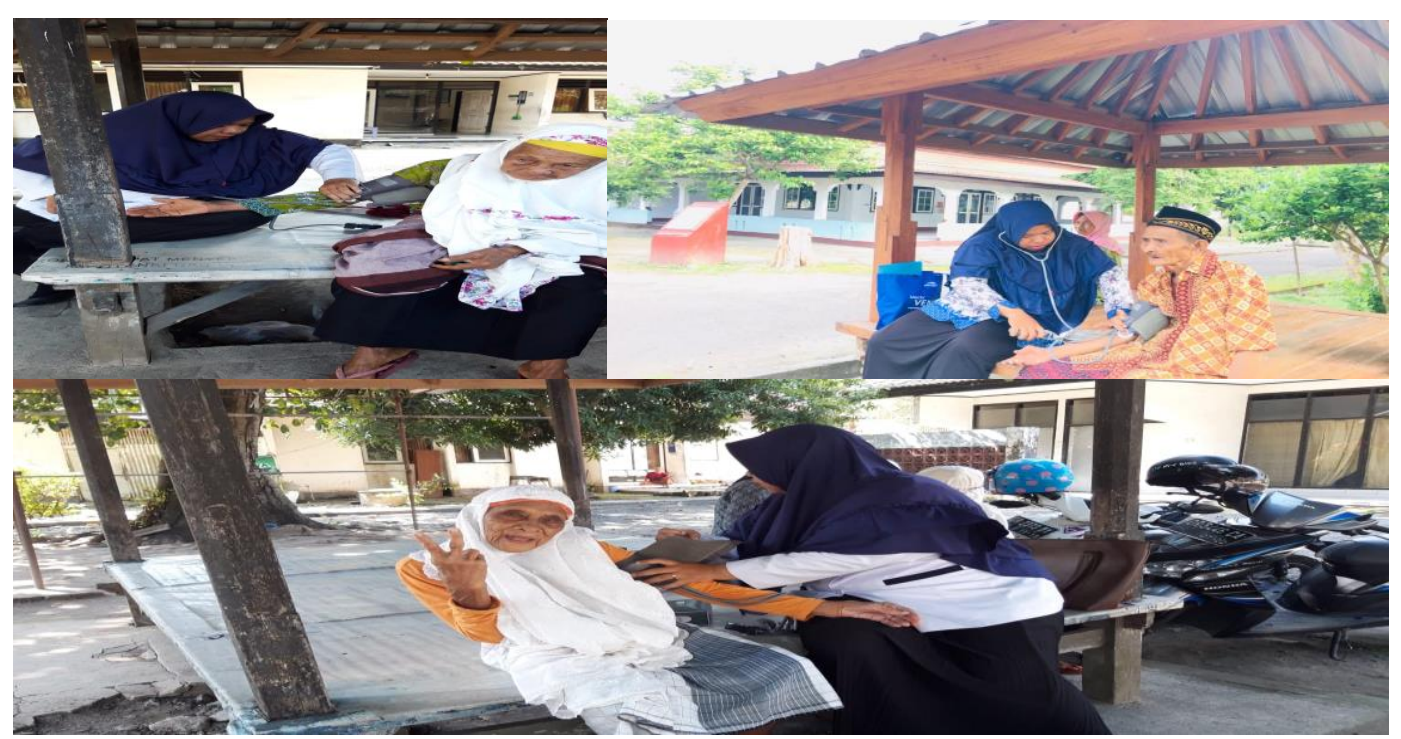

Tabel 1. Distribusi Responden berdasarkan Usia di Panti Sosial Tresna Werdha Provinsi Nusa Tenggara Barat

\begin{tabular}{cccc}
\hline No & Usia & Frekuensi & $\%$ \\
\hline 1 & $<60$ tahun & 1 & 6,3 \\
2 & $\geq 60$ tahun & 15 & 93,7 \\
\hline
\end{tabular}

Tabel 2. Distribusi Responden berdasarkan Jenis Kelamin di Panti Sosial Tresna Werdha Provinsi Nusa Tenggara Barat

\begin{tabular}{cccc}
\hline No & JenisKelamin & Frekuensi & $\%$ \\
\hline 1 & Laki-laki & 4 & 25 \\
2 & Perempuan & 12 & 75 \\
\hline
\end{tabular}

Tabel 3. Distribusi Tekanan Darah Lansia Penderita Hipertensi Sebelum dan setelah Melaksanakan Sholat Dhuha di Panti Sosial Tresna Werdha Provinsi Nusa Tenggara Barat

\begin{tabular}{llccc}
\hline Variabel & TD & N & P Value \\
\hline & & 130 & 1 & \\
TD sebelum & 140 & 1 & \\
Shalat dhuha & 150 & 11 & \\
& & 160 & 1 & \\
Pair & 170 & 1 & 0.000 \\
& & 180 & 1 & \\
& TD setelah & & & \\
& Shalat dhuha & 130 & 3 & \\
& & 140 & 10 & \\
& & 150 & 1 & \\
& 160 & 1 & \\
\hline
\end{tabular}

(sumber: Data primer 2020) 
ISSN (online): 2722-2055 https://jurnal.umj.ac.id/index.php/ASSYIFA
AS-SYIFA: Jurnal Pengabdian dan Pemberdayaan Kesehatan Masyarakat

Berdasarkan tabel di atas di dapatkan peserta pada kegiatan pengabdian ini terdiri dari laki-laki dan perempuan, mayoritas peserta berusia diatas 60 tahun sebanyak 15 orang (93.7\%), mayoritas peserta berjenis kelamin perempuan sebanyak 12 orang (75\%), Berdasarkan table di atas didapatkan hasil Uji Paired T-test nilai tekanan darah systole setelah melakukan terapi shalat dhuha yaitu $p$ value 0,000 . Artinya nilai $p$ value yang diperoleh lebih kecil dari 0,05 hal ini menunjukkan ada pengaruh yang signifikan dari terapi shalat dhuha terhadap penuruan tekanan darah pada lansia penderita hipertensi.

Resiko terjadinya tekanan darah tinggi sejalan dengan bertambahnya usia, sebagaimana di terlihat pada teori yang menyatakan bahwa pada lansia arteri besar kehilangan kelenturan dan menjadi kaku dan darah harus melalui pembuluh darah yang lebih sempit dari pada biasanya sehingga mengakibatkan naiknya tekanan darah. Tekanan darah tinggi banyak terjadi pada usia dewasa tengah yaitu diatas 40 tahun (Hartanti \& Mifbakhuddin, 2015). Perempuan memiliki resiko lebih besar untuk menyandang hipertensi karena dipengaruhi oleh kadar hormone estrogen. Kadar hormone estrogen akan semakin menurun seiring meningkatnya usia. Tatalaksana penanganan hipertensi adalah mengoptimalkan tensii agar tidak terlalu tinggi dan salah satu tindakan pengelolaan hipertensi adalah menggunakan penanganan tanpa obat yaitu menciptakan keadaan rileks sehingga mampu menurunkan tekanan darah. Shalat dhuha dapat dijadikan salahsatu alternative dalam mempertahankan tekanan darah tetap stabil, karena dalam shalat dhuha bisa menentramkan hati dan menjadikan organ-organ kita menjadi rileks. Pada saat kondisi tubuh sedang rileks tubuh akan mempengaruhi kelenjar pituitary yang akan menghasilkan hormon endorphin. Hormone endorphin merupakan neuromodulator yang bekerja secara tidak langsung dengan menurunkan efek partikuler neurotransmitter berupa katekolamin. Penurunan kadar katekolamin dalam pembuluh darah dapat mengakibatkan denyut jantung berkurang dan tekanan darah menjadi turun. Keberhasilan terapi shalat dhuha ini tentunya tidak terlepas dari yang membimbing proses berjalannnya pelaksanaan shalat dhuha, lingkungan yang nyaman serta kondisilansia itu sendiri. Keadaan lingkungan, serta kekhusukan lansia dapat mempengaruhi keberhasilan terapi shalat dhuha itu sendiri. Menurut Mamangkey, Yustisia Pratiwi (2019) Ketika seseorang melaksanakan shalat dhuha akan menurunkan tingkat stress sehingga tekanan darah juga menjadi stabil.

\section{Kesimpulan Dan Saran}

Kesimpulan pada kegiatan pengabdian ini didapatkan bahwa peserta terdiri dari laki-laki dan perempuan mayoritas peserta berjenis kelamin perempuan, mayoritas peserta berusia diatas 60 tahun dan adanya penurunan tekanan darah setelah dilakukan terapii shalat dhuha. Oleh karena itu shalat dhuha harus tetap dilaksanakan untuk membantu menjaga Tekanan darah lansia tetap stabil.

\section{Ucapan Terima Kasih}

Ucapan terima kasih Kami haturkan kepada pihak Panti Sosial Tresna Werdha Provinsi Nusa Tenggara Barat selaku mitra pada pengabdian ini, yang banyak memberika kontribusi sehingga proses pengabdian ini bisa berjalan. 


\section{Daftar Pustaka}

Al-Mahfani, M. Khalilurrahman. 2008. Buku Pintar Shalat: Pedoman Shalat Lengkap Menuju Shalat Khusyuk. Jakarta: Wahyu Media.

Anggraini, Ade, D., Waren, A., Situmorang, E., Asputra \& Siahaan, S .2009. Faktor-Faktor yang Berhubungan dengan Kejadian Hipertensi pada Pasien yang berobat di Poliklinik Dewasa Puskesmas Bangkinang. Fakultas Kesehatan. Universitas Riau. Files of DrsMed-FK UNRI : 1-41

Aziza, Lucky. 2007. Hipertensi: The Sillent Killer. Jakarta: Ikatan Dokter Indonesia.

Azizah, Lilik Na’rifatul. 2011. Keperawatan Lanjut Usia Edisi 1. Yogyakarta: Graha Ilmu

Benson, Herbert dan Willam Proctor. 2000. Keimanan yang Menyembuhkan: Dasar-dasar Respons Relaksasi. Bandung: Penerbit Kaifa.

Corwin, Elizabeth J. 2009. Patofisiologi: buku saku Edisi 3. Jakarta: EGC. Depkes RI. Masalah Hipertensi di Indonesia. 2012. www.depkes.go.id/index.php/berita/pressrelease/1909-masalah-hipertensidiindonesia.html

Dewi, Sofia R. 2014. Buku Ajar Keperawatan Gerontik. Yogyakarta: Deepublish

Dikes Prov. NTB. 2019. Profil Kesehatan Provinsi Nusa Tenggara Barat Tahun 2018.

Depkes. 2016. Profil kesehatan indonesia 2015. Departemen Kesehatan Republik Indonesia : Jakarta

Dalimartha, S., et al. 2008. Care Your Self: Hypertension. Jakarta: Penebar Plus.

Dina T, Elperin, et al, 2013, A Large Cohort Study Evaluating Risk Factors Assosiated With Uncontrolled Hypertension, The Journal of Clinical Hypertension, Vol. 16 No.2

Elzaky, Jamal Muhammad. 2011. Buku Induk Mukjizat Kesehatan Ibadah

Hartanti, M. P., \& Mifbakhuddin. 2015. Beberapa Faktor yang Berhubungan dengan Kejadian Hipertensi pada Petani. Jurnal Kesehatan Masyarakat Indonesia (JKMI), Vol.10 No.1

Kanisius. Iskandar, Alex dan Endi Novianto. 2008. Sehat, Kaya, dan Bahagia Duniawi Spiritual. Jakarta: PT Elex Media Komputindo.

Kozier, Barbara dan Glenora Erb. 2009. Buku Ajar Praktik Keperawatan Klinis Ed. 5. Jakarta: EGC.

Mamangkey, Yustisia Pratiwi. 2019 Pengaruh shalat dhuha terhadap tingkat stres dan tekanan darah pada lansia dengan hipertensi derajat 1. Undergraduate thesis, Widya Mandala Catholic University Surabaya 
Riskesdas. 2018. Riset Kesehatan Dasar 2018. Jakarta : Badan Penelitian dan Pengembangan Kesehatan, Departemen Kesehatan, Republik Indonesia Stuart dan Sundeen. (2006). Buku saku keperawatan. Edisi 3. Jakarta: EGC

Sudiarto, at al. 2007. Pengaruh Terapi Relaksasi Meditasi Terhadap Penurunan Tekanan Darah Pada Lansia Dengan Hipertensi Di Wilayah Binaan Rumah Sakit Emanuel Klampok Banjarnegara. Jurnal Keperawatan Universitas Jenderal Soedirman Purwokerto.

Susanto dan Masri Sareb Putra. 2010. Management Gems: Applying Management Wisdom in Life. Jakarta: Gramedia Pustaka Utama.

Tebba, Sudirman. 2008 . Nikmatnya Shalat Khusyuk. Jakarta: Pustaka Irvan. 
Volume. 2 No. 1 tahun 2020

Mei 2021 - November 2021
ISSN (online): 2722-2055

https://jurnal.umj.ac.id/index.php/ASSYIFA
AS-SYIFA: Jurnal Pengabdian dan

Pemberdayaan Kesehatan Masyarakat 